Editorial

\title{
Quality Improvement in Medical Education
}

\author{
Sanjeev Misra ${ }^{1}$ \\ ${ }^{1}$ Director, All India Institute of Medical Sciences, Jodhpur, Rajasthan, \\ India
}

Ann Natl Acad Med Sci (India) 2019;55:117-118

During our medical school days, one of the professors used to ask us to keep a notebook labeled as Jigyasa Diary (Curiosity Diary), and one had to note down any question that came to our mind. Questions could be related to any field. It was not mandatory but optional. This strategy worked, and when few students started maintaining and posing questions, the others followed the suit. Such an exercise leads to the development of a curious mind. This strategy by our medical teacher led us to believe that if offered a choice, it can inculcate a habit of lifelong learning among students. This is called change management or quality improvement (QI) in the teaching process.

Medical education globally has come to an age and is still developing driven by the changing needs of the society and societal expectations. The ultimate aim of medical education is to develop health resources, which, in turn, help develop a healthy society. Toward this end, medical institutions have been entrusted to prepare and nurture the physicians of tomorrow. They are also entrusted with the responsibility of developing and sustaining a habit of continuous professional development among health care workers. To promote this development, institutions, societies, and associations organize continuing medical education activities. It is a well-known fact that the impact of education on behavioral changes is difficult to assess in a short term as the outcomes are visible much later. In fact, medical education has become a process, has evolved much more with time, and still offers opportunities for positive change.

The Medical Council of India (MCI) was established in 1934 under the Indian Medical Council Act, 1933, with the main function of establishing uniform standards of higher qualifications in medicine and recognizing medical qualifications in India and abroad. The apex body was mandated for the promotion and maintenance of excellence in medical education. Through a lot of deliberations and discussions among the stakeholders and experts during the past 6 years, the MCI has recently introduced "Competency-based Medical Education Curriculum" throughout India from July 2019 session with an emphasis on skill and proficiency development aligned with the need of the society. The National

Address for correspondence

Sanjeev Misra, MS, MCh, FRCS, FICS, FACS, FAMS, FNASc, Director, All India Institute of Medical Sciences, Jodhpur, Rajasthan 342005, India

(e-mail: misralko@gmail.com)
DOI https://doi.org/

10.1055/s-0039-3402363

ISSN 0379-038X.

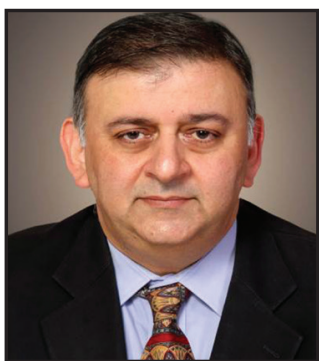

Sanjeev Misra

Medical Commission Bill was introduced in 2019 and seeks to repeal the Indian Medical Council Act, 1956. It will provide for a medical education system that ensures (1) availability of adequate and high-quality medical professionals, (2) adoption of the latest medical research by medical professionals, (3) periodic assessment of medical institutions, and (4) an effective grievance redressal mechanism.

It is amply clear that there is a need for continuous QI in medical education. When we talk of QI in medical education, it can have two connotations: (1) to have QI curriculum in medical training for both undergraduates and postgraduates and (2) to improve the process of medical education through the principles of QI. There is lot of debate on the first one: whether we should introduce QI in UG training so early? Although the evidences are in favor, understanding QI may be complex for undergraduates. What I am referring to QI in medical education is teaching and learning processes.

Let us define QI in health care. There are many definitions but most refer to it as "systematic and continuous actions that lead to measurable improvement in health care services and the health status of targeted patient groups." The Institute for Healthcare Improvement (IHI) says: "the science of improvement is an applied science that emphasizes innovation, rapid-cycle testing in the field, and spread in order to generate learning about what changes, in which context(s), produce improvement(s)." IHI further states that "It is characterized by the combination of expert subject knowledge with improvement methods and tools." It is multidisciplinarydrawing on clinical science, systems theory, psychology, statistics, and other fields. ${ }^{1}$ QI also involves developing theories for change, testing them, measuring their impact with data that is collected in "real time," and refining theories of change using an iterative trial and learning methodology, for example, PDSA (Plan, Do, Study, Act) cycles. ${ }^{2}$ Moreover, QI differs from audit as it does not need to be based on a standard and may even be based on a hunch or intuition. However, it does require a lot of training.

Used earlier in agriculture and manufacturing environments that are built on processes, many strategies and tools

(C)2019 National Academy of

Medical Sciences (India)

\section{License terms}

$($ () (1) $\Theta \circledast$ 
for QI are in existence now, and any one of them can be used in health care and medical education. The basic tenets of QI are based on following principles: (1) adoption by institutes through hands-on projects, (2) defining quality and have consensus, (3) measure improvement, (4) use QI tools and PDSA cycles, and (5) learn from variation in data (control charts, run charts, pareto charts, etc.).

In medical education, there are multiple processes, such as institutional policies, classroom environment, social diversity of the class, the facilitator qualities, teaching methods, use of the type of teaching media, assessment method, assessment environment, and various psychological factors facilitating learning. It is not necessary to change everything drastically in one go. It is recommended, as per the QI principles, to start small and make big difference.

Curriculum for undergraduation is being implemented in all medical colleges in India from July 2019 coupled with faculty development programs. At the same time, reasonable flexibility is maintained since the MBBS program is still time-bound. Even then, there is scope for QI in our curriculum and its delivery.

The University of Vermont proposed a new approach in moving away from didactic lectures. ${ }^{3}$ The concept of flipped classroom is rapidly expanding to medical education and is partly replacing traditional lectures. The most important cited reason is that it offers increasing student engagement, whereby basic and fundamental information is provided to the students before the class, and the class time is then used for deep learning and application of knowledge. ${ }^{4}$ When introducing the flipped classroom concept, many challenges may be encountered. Content distributed before class may not be studied or viewed. Using principles of QI, e-mail reminders, SMS, and coaxing may be used and their impact can be seen. These small changes will make flipped classroom more rewarding and also provide better impact on student learning. These same QI change management can be shared with faculty members as best practices to improve learning.

The same concept can be used for student attendance, which can be a problem with the advent of technology. If we perform root cause analysis, many factors may emerge. Any one or more may be chosen for the QI process keeping in mind what we are trying to accomplish, how we will know that change is improvement, and to use the PDSA cycle to ascertain what changes we make that results in improvement.

For change management to be successful, stakeholders' involvement and their engagement is very crucial. The Head of Institutions, Principals, Deans, and Heads of the Departments and medical education unit teams assume importance as their involvement augment the process.
Richman et al have demonstrated that the systematic process used by their team to collect data from students and faculty helped facilitate QI in a key course in phase 1 of their Learning-focused, Experiential, Adaptive, Rigorous and Novel (LEARN) curriculum introduced in 2015.

They have shown that a structured QI process can enable the faculty to raise the level of student satisfaction and course grades by better integrating basic and clinical sciences, engaging course faculty in closer collaboration, and improving assessments. ${ }^{5}$

In India, a highly dedicated working group is mentoring health care professionals and promoting QI on a large scale in health care. ${ }^{6}$ Efforts ranging from simple measures to improve newborn care, waiting time in emergency and designing learning platform for QI training, the group is proactively involved in innovations and capacity building with support from various national and international agencies.

We hope that using QI principles in medical education, small changes will yield high dividends and will catalyze our health care system toward optimal performance.

\section{Conflict of Interest}

None declared.

\section{Acknowledgments}

I am immensely grateful to Dr. Kuldeep Singh for sharing pearls of wisdom during the course of preparation of this Editorial. I also show my gratitude to two anonymous reviewers for their insights. However, if there are any errors, these have nothing to do with the comments of these esteemed persons.

\section{References}

1 Institute for Healthcare Improvement. Science of Improvement. Available at: http://www.ihi.org/about/Pages/Scienceoflmprovement.aspx. Accessed December 5, 2019

2 Walshe K. Understanding what works-and why-in quality improvement: the need for theory-driven evaluation. Int J Qual Health Care 2007;19(2):57-59

3 Schwartzstein RM, Roberts DH. Saying goodbye to lectures in medical school - paradigm shift or passing fad? N Engl J Med 2017;377(7):605-607

4 Singh K, Mahajan R, Gupta P, Singh T. Flipped classroom: a concept for engaging medical students in learning. Indian Pediatr 2018;55(6):507-512

5 Richman PS, Olvet DM, Ahmad S, Chandran L. Use of student feedback to drive quality improvement (QI) in a preclinical U.S. medical school course. Med Educ Online 2019;24(1):1583968

6 Deorari A, Livesley N. Delivering quality healthcare in india: beginning of improvement journey. Indian Pediatr 2018;55(9):735-737 